\title{
Cultural management of bluetongue virus vectors
}

\author{
Bradley A. Mullens o John L. Rodriguez
}

\section{Surveys and experiments in dairy wastewater ponds showed that pond design and management af- fect populations of blood-feeding gnats that spread bluetongue vi- rus. Avoiding shallow evaporation beds, changing water levels weekly, and keeping manure pollu- tion below 300 to 400 milligrams COD per liter will help control gnats.}

Bluetongue disease is common in wild and domestic ruminants in many areas of California. It can cause reproductive problems in cattle and sheep; sheep are more susceptible and may die. Livestock producers may also be economically affected by trade restrictions on animals or semen. The disease is caused by a virus transmitted primarily through blood-feeding by tiny gnats in the genus Culicoides. Presently, five types of the virus are in California. Management of the disease has been difficult, partially because of inadequate knowledge of (1) the virus, (2) its relationships with vertebrate and insect hosts, and (3) the ecology of the gnats that transmit it.

The principal vector in most of the United States is Culicoides variipennis, which is widespread in California. This tiny fly often is found near livestock. Eggs are laid in surface mud at the edge of water and hatch in about 3 days. Larvae develop through four stages and pupate above the waterline. The entire life cycle requires 20 to 35 days in warm weather and 6 to 8 weeks during the winter in southern California.

We have observed larvae in high densities in manure-polluted water sources on southern California dairies in late summer and fall. The immature stages also are common in certain saline or alkaline pools and can occur at lower densities in a wide variety of water sources. We conducted surveys in dairy wastewater ponds in southern California and studied habitat characteristics that appeared to inhibit colonization or survival of $C$. variipennis.

\section{Dairy wastewater survey}

Approximately 140,000 gallons of wastewater are produced per week on a typical California dairy of about 500 cows. This water is used immediately to irrigate adjacent pastures or is stored in ponds or catch basins. There it percolates and evaporates or is pumped out for irrigation.

We sampled at least five times at each of 26 southern California dairy wastewater ponds that were extremely variable in design. Generally, they were either (1) relatively shallow (less than 3 feet deep) evaporation beds or (2) deeper (more than 6 feet), more permanent ponds used for longer term water storage. The evaporation beds were not often pumped for irrigation, but the storage ponds were. The evaporation beds had shallower slopes (average $15^{\circ}$ ) and sometimes were visited by cattle, while the storage ponds had steeper slopes (average $28^{\circ}$ ) and seldom were visited by cattle.

We used chemical oxygen demand (COD) to determine the amount of organic pollution. Although the visible manure solids were greater in the storage ponds, the water was cleaner there (average 708 milligrams COD per liter [mg COD/liter]) than in the evaporation beds (average $1,800 \mathrm{mg}$ COD/ liter). The storage ponds also had much lower phytoplankton densities, which were assessed by microscopic examination of water samples in the laboratory, and expressed as phytoplankton volume per sample. Food requirements of larvae are poorly known, but the storage ponds held water for longer periods and tended to have primarily bacteria. Possibly, phytoplankton are important food sources for C. variipennis larvae. Alternatively, the correlation could be indirect.

About twice as many C. variipennis larvae were found in evaporation beds (average 106 larvae/30 milliliters [1 ounce] of shoreline mud) as in the storage ponds (average 52 larvae $/ 30 \mathrm{ml}$ ). Although the factors determining larval population density were interrelated, the most critical determinants of habitat suitability appeared to be pond slope, level of manure pollution (and re- lated phytoplankton densities), the pumping of ponds for irrigation, and length of time the habitats held water. Steeper slopes probably reduce the habitable mud surface to a narrow band at the water's edge, particularly as pollution increases and oxygen available to the larvae decreases. Slopes should be greater than about $30^{\circ}$ to reduce numbers of larvae substantially (fig. 1). Pond edge slope, as well as water quality, may vary in individual ponds depending on water level.

\section{Pollution effects}

Manure loading was studied in experimental wastewater ponds, where variable factors could be controlled. Eight ponds were dug on a dairy in Mira Loma, California, in October, when our research indicated local $C$. variipennis populations were highest. Ponds were filled with water, loaded with manure ( 1 cubic meter per pond), and sampled every 2 or 3 days for 56 days. Water was added every 1 to 2 days at first to allow the ponds to seal. Larvae were found 10 days after the first addition of water, which was only a few days after ponds began to hold water for 2 days or more at a time. The first adults emerged, under cooler fall conditions, 35 days after the first addition of water (fig. 2). These results confirmed that $C$. variipennis colonizes new habitats very quickly.

Through the following spring, we maintained ponds, monitored insects, and kept manure loading at a constant, low level. Beginning July 1, each pond was loaded with manure at a different rate until midOctober. Ponds loaded with more than 3.3 liters of fresh manure per cubic meter per week (more than $516 \mathrm{mg}$ COD/liter of water) showed substantial increases in gnat abundance, whereas those loaded with less than 1.6 liters per cubic meter per week (less

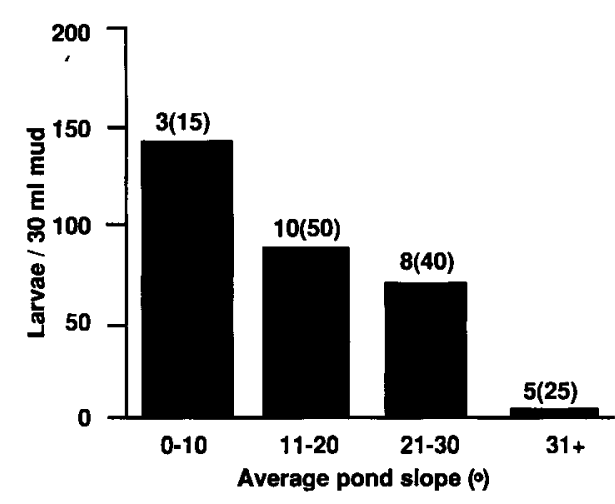

Fig. 1. Average C. variipennis densities show that slopes of dairy wastewater ponds should be more than $30^{\circ}$ to reduce numbers of larvae substantially. [Number of ponds (number of sample dates) appear above bars.] 
than $306 \mathrm{mg}$ COD/liter) showed only slight increases in density (less than seven times) above the low pretreatment levels. Larval densities were 30 to 89 times as high as pretreatment in ponds loaded with 13 and 26 liters of fresh manure per cubic meter per week. Also, larger C. variipennis were produced from the more polluted ponds. The larger gnats lay more eggs and probably live longer, and thus may be better bluetongue virus vectors.

The optimal pollution range appears to be 500 to $1,500 \mathrm{mg}$ COD/liter. Higher levels are not strictly limiting, whereas levels below 300 to $400 \mathrm{mg}$ COD/liter clearly inhibit gnat colonization or development.

\section{Water level effects}

Larvae of $C$. variipennis generally follow slowly fluctuating water levels in ponded water sources, although there also are daily movement patterns by the older larvae. Larvae move to stay in surface mud near the waterline, and pupae (normally found just above the waterline) float free and relocate if inundated by rising water. However, we found significantly lower numbers of this species in ponds that were pumped for irri-
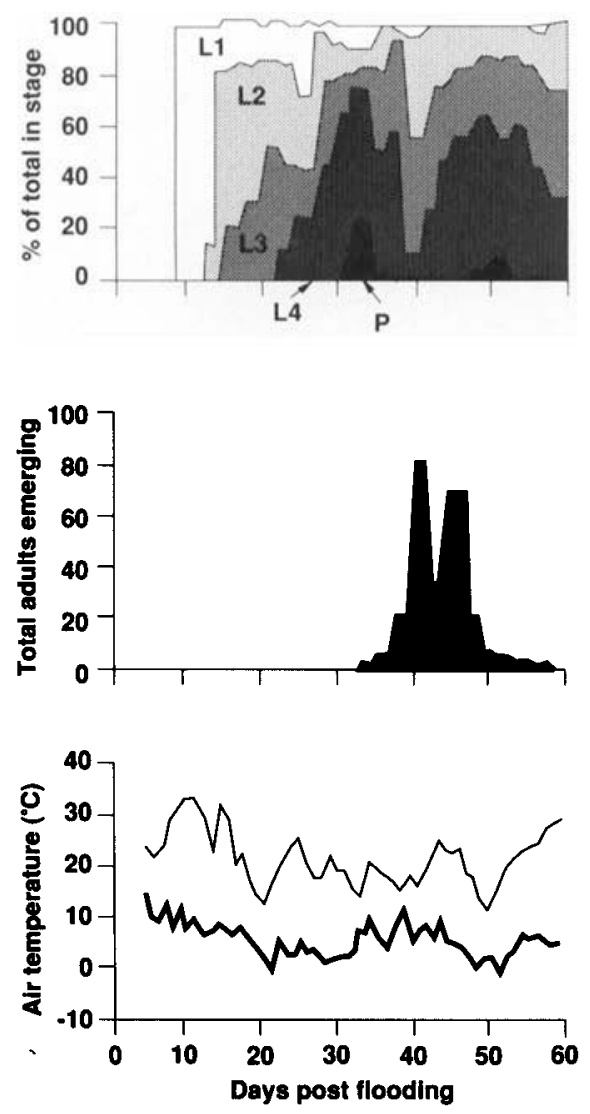

Fig. 2. Two new dairy wastewater ponds in the Chino Basin were rapidly colonized by $C$. variipennis between October and December: top, progression of four larval stages (L1-L4) and pupae (P); center, adult emergence; bottom, maximum and minimum air temperatures. gation, suggesting that water level changes are a possible factor. Rapid fluctuations in water level may also occur with rainfall or with changes in water storage (e.g., rotating ponds) or irrigation. Because the immature insects are so small (less than 0.2 inch long), a rapid drop in water level might strand the eggs and larvae above the waterline, where they could perish as a result of drying, excessive heat, or starvation.

The eight experimental dairy wastewater ponds were sampled weekly for 2 months before the trials began. Ponds were then paired according to density of $C$. variipennis larvae. One of each pair was designated to have the water level held stable (water added twice a week), while water levels were changed in the other. Manure loading was kept at a low and constant level in all ponds throughout the study. In the fluctuating ponds, water levels were dropped rapidly (edge receded approximately 2 inches a minute). The new, lower waterline was almost 10 feet from the previous waterline. The level was kept low for 18 days, raised at the same rate, kept there for 10 days, dropped again for 18 days, and raised again (two full cycles). We followed a sampling plan that allowed us to observe both adult emergence and trends in numbers and movement of larvae or pupae.

Following a drop in water level, most larvae and pupae remained at the old waterline. Pupation and emergence continued to occur there for approximately 5 to 8 days (fig. 3). Approximately $80 \%$ to $90 \%$ of the young larvae apparently were killed within 7 days after the drop in water level, but a few older larvae remained alive up to 18 days after the drop, especially in mud over a half inch deep.

After each drop, increased egg-laying occurred at the new, lower waterline, and emergence of these adults began 14 to 18 days later (fig. 3). When the water rose, larvae and pupae moved to the higher waterline within 3 hours to 2 days. Young larvae were less able to complete this migration and were lost. The same trends were repeated during both water level cycles.

\section{Conclusions}

We now have a better understanding of habitat requirements for $C$. variipennis. In general, shallow ponds that catch and hold wastewater for at least 8 to 10 days during warm weather (probably at least 3 to 5 weeks during cooler weather) are suspect as prime sources of the gnat that transmits bluetongue virus. This insect is well adapted to colonizing new habitats, can develop from egg to adult in as little as 12 to 14 days under optimal conditions, and will survive to pupate in moist soil if it has developed sufficiently in the larval stage.

The deeper storage ponds have several features that do not favor these gnats. First these sites have usually held water for a longer time. Compared with recently flooded sites, the microbial flora in older habitats tends to include bacteria and rotifers rather than phytoplankton. The extended time factor also may allow establishment of the natural enemies of $C$. variipennis, or older habitats may be less attractive for egg-laying. Second, the deeper ponds tend to have steeper sides. In those with slopes greater than $30^{\circ}$, we found low numbers of larvae. Depending on soil type, a steep edge may not be feasible or may require reinforcement. Third, since these ponds often are used for irrigation, water levels vary, a characteristic that may directly reduce habitat quality and immature gnat survival.

Some of the more permanent ponds actually had water that was too clean for Culicoides larvae. Water pollution can be kept low enough to reduce gnat abundance. Inflow from feed alleys flushed twice daily with new water dilutes some ponds. Extensive flow of wastewater over pasture and into
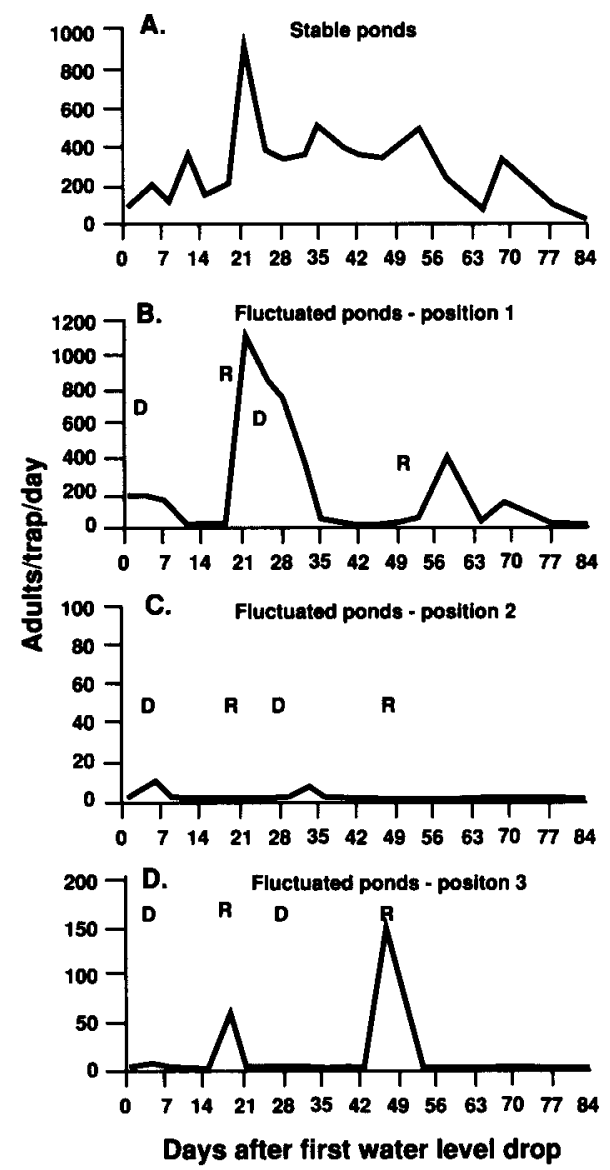

Fig. 3. Emergence of $C$. variipennis adults from dairy wastewater ponds with stable or fluctuating water levels. Position 1 was the water's edge when the water level was high; position 2, intermediate; position 3, water's edge when the level was low. Distance between positions was 5 feet. $D$ and $R$ indicate drop and rise in water level. 


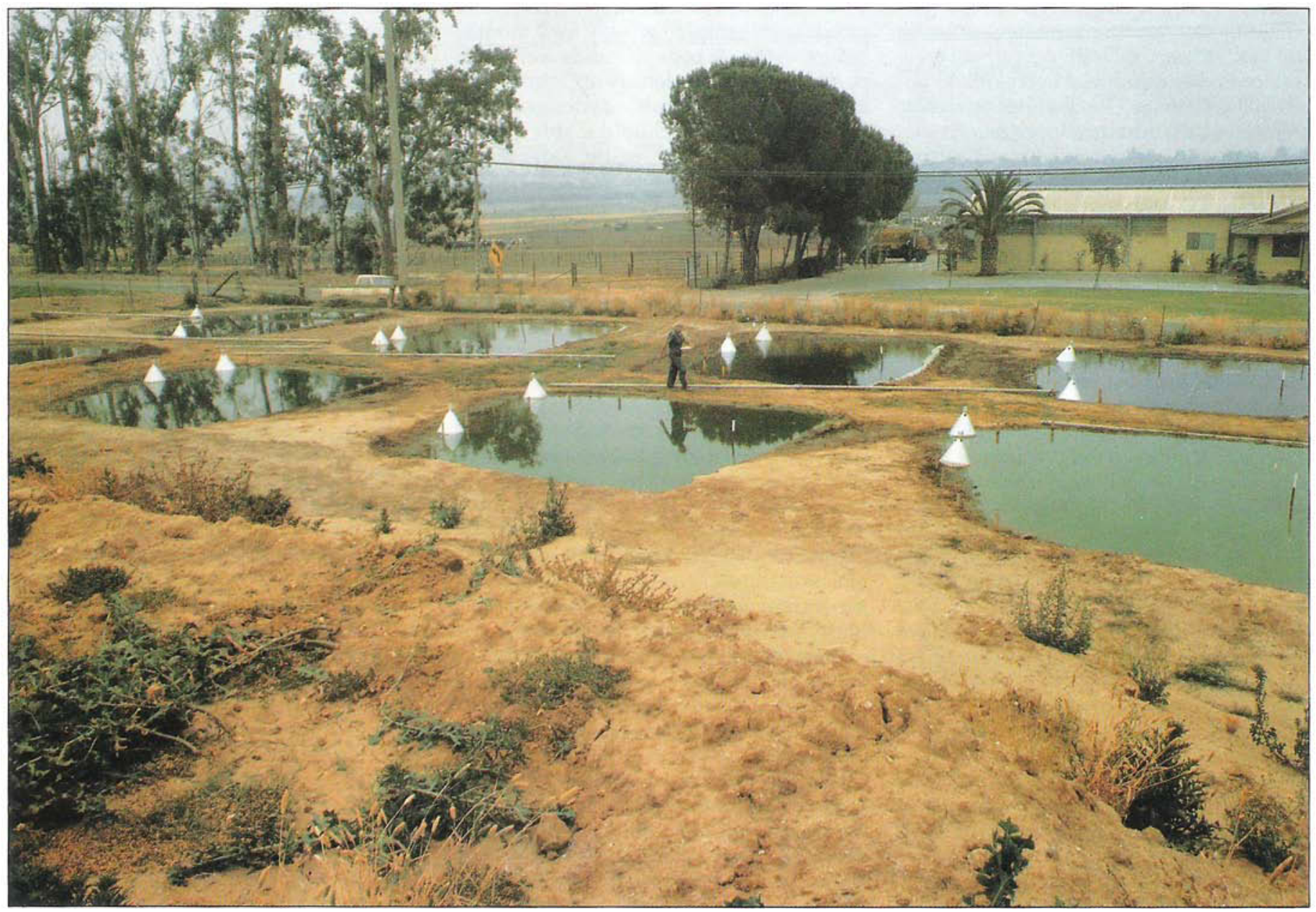

Experimental dairy wastewater ponds were used to study effects of manure loading and changes in water level on populations of the Culicoides gnats that spread bluetongue virus of cattle and sheep. The white cones are aluminum emergence traps used to collect adult gnats.

shallower ponds may produce biological filtering, which results in water entering the ponds with COD levels less than 300 to 400 mg/liter.

The larvae live at the water's edge and can follow levels that slowly recede with evaporation or percolation. They also follow either slowly or rapidly rising water levels, which result from irrigation runoff or rainfall. After a rapid rise, however, most early stages die. Rapid water level drops in wastewater ponds expose new, organic substrate that can increase gnat egg-laying. However, rapid drops also strand most of the immatures above waterline, where they die within 7 days. Adult emergence from wastewater ponds can be reduced by rap- idly changing water levels every 7 days.

The same findings with regard to pollution, slope, and water levels might apply to other types of habitats such as irrigation ditches. Because $C$. variipennis can be produced in large numbers from small habitats, smaller areas of standing polluted water, such as overflow from watering troughs or stock ponds, should not be overlooked. Many of these habitats can be eliminated entirely with regular maintenance.

Water sources can thus be designed and managed to reduce gnat populations. We still lack critical information on C. variipennis dispersal and its capacity for spreading bluetongue virus that may affect design and management strategies for insect control.
Dairy producers may not find it economical to modify existing water sources if neighboring producers do not. However, producers who are planning new facilities will want to take design and management factors into account.

Bradley A. Mullens is Associate Professor, and John L. Rodriguez is Staff Research Associate, Department of Entomology, University of California, Riverside. The authors especially appreciate the cooperation of Jacob Vandenberge and the other dairymen who allowed them to visit their facilities. This article is a synthesis of more detailed articles in the Journal of Medical Entomology 25:441-51, and two articles in Volume 26 (in press). 